\title{
Aplicação de lipase e monoglicerídeo em pão de forma enriquecido com fibras
}

\author{
Application of lipase and monoglyceride in fiber enriched pan bread \\ Kelly Moreira GANDRA ${ }^{1}$, Michelle DEL BIANCHI ${ }^{1}$, Vanessa Padovani GODOY ${ }^{1}$, \\ Fernanda Paula Collares QUEIROZ ${ }^{1}$, Caroline Joy STEEL ${ }^{1 *}$
}

\begin{abstract}
Resumo
Neste trabalho, estudou-se a aplicação da enzima lipase e do emulsificante monoglicerídeo em pão de forma enriquecido com fibras, com o objetivo de verificar a possibilidade de substituição do emulsificante pela enzima. Inicialmente, foi realizada a caracterização das matériasprimas principais (farinha e farelo de trigo). Os pães de forma foram elaborados pelo método de massa direta. Foi utilizado um planejamento experimental do tipo composto central rotacional com duas variáveis independentes: i) dosagem de lipase; e ii) dosagem de monoglicerídeo e, paralelamente, realizou-se um teste controle (sem adição de lipase e monoglicerídeo) para comparação. As variáveis dependentes foram as características de qualidade dos pães: i) volume específico; ii) aceitação sensorial (aparência, textura, aroma e sabor); e iii) vida de prateleira avaliada pela umidade do miolo e firmeza dos pães após 1, 4 e 7 dias do forneamento. Dentro das faixas estudadas, foi possível verificar que somente a umidade dos pães no quarto e sétimo dia após o processamento foi influenciada pela variação das dosagens de lipase e monoglicerídeo. $\mathrm{Na}$ avaliação sensorial, verificou-se que as notas médias atribuídas aos pães do teste controle foram inferiores à menor nota média dos ensaios do planejamento experimental, com exceção do sabor e aroma. Como não foi possível obter modelos matemáticos para todas as respostas, foram selecionados os ensaios 5 ( $1 \%$ monoglicerídeo), 7 ( 25 ppm lipase) e 9 ( 25 ppm lipase e $1 \%$ monoglicerídeo) do planejamento experimental, e o teste controle, para a avaliação dos resultados por análise de variância. Nas condições em que os ensaios foram conduzidos e para as faixas de lipase (0 a $50 \mathrm{ppm})$ e monoglicerídeo ( 0 a $2 \%)$ estudadas, verificou-se a possibilidade de substituir o monoglicerídeo por lipase em formulação de pão de forma enriquecido com fibras.
\end{abstract}

Palavras-chave: pão de forma; lipase; monoglicerídeo; fibras.

\begin{abstract}
In this work, the application of lipase and monoglyceride in fiber enriched pan bread was studied, to verify the possibility of substituting the emulsifier by the enzyme. Initially, the main raw materials (flour and wheat bran) were characterized. The pan breads were produced using the straight dough method. A central composite rotational design was used, with two independent variables: i) lipase dosage; and ii) monoglyceride dosage and, in parallel, a control test was carried out (without the addition of lipase and monoglyceride) for comparison. The dependent variables or responses were the quality characteristics of the breads: i) specific volume; ii) sensory acceptance (appearance, texture, aroma and taste); and iii) shelf life evaluated by crumb moisture and firmness after one, four and seven days from baking. Within the ranges studied, it was possible to verify that only crumb moisture on the fourth and seventh days after processing was influenced by the variation of the lipase and monoglyceride dosages. In the sensory evaluation, it was observed that the average scores attributed to the control breads were lower than the lowest average of the experimental design trials, except for taste and aroma. As it was not possible to obtain mathematical models for all the responses, Assays 5 ( $1 \%$ monoglyceride), 7 (25 ppm lipase) and 9 (25 ppm lipase and 1\% monoglyceride) of the experimental design, and the control test, were selected for the evaluation of the results by analysis of variance. In the conditions used and for the dosages of lipase ( 0 to $50 \mathrm{ppm}$ ) and monoglyceride ( 0 to $2 \%$ ) used, the possibility to substitute monoglyceride by lipase in fiber enriched pan bread was verified.
\end{abstract}

Keywords: pan bread; lipase; monoglyceride; fibers.

\section{Introdução}

O pão é o produto obtido pela coç̧ão, em condições tecnologicamente adequadas, de uma massa fermentada, ou não, preparada com farinha de trigo e/ou outras farinhas que contenham naturalmente proteínas formadoras de glúten ou adicionadas das mesmas e água, podendo também conter outros ingredientes. A classificação "pão de forma" é atribuída ao produto obtido pela cocção da massa em formas, apresentando miolo elástico e homogêneo, com poros finos e casca fina e macia (BRASIL, 2006).
Vários tipos de fibras podem ser acrescentados aos produtos de panificação, na forma de farinhas integrais de sementes (trigo, aveia, centeio, milho, soja, aveia, cevada, girassol, linhaça, arroz e sorgo) ou fibras isoladas de frutas e outros vegetais (maçã, pêra e uva). Além do aspecto nutricional, as fibras apresentam, em sua maioria, custo baixo e são facilmente encontradas comercialmente (POMERANZ, 1987). De acordo com Stauffer (1990), existem duas razões para se adicionar fibras em pães, sendo a

Recebido para publicação em 8/3/2007

Aceito para publicação em 19/10/2007 (002125)

${ }^{1}$ Departamento de Tecnologia de Alimentos, Faculdade de Engenharia de Alimentos, Universidade Estadual de Campinas, E-mail: cjsteel@yahoo.com

${ }^{*}$ A quem a correspondência deve ser enviada 
primeira, o aumento do teor de fibra alimentar, e a segunda, o decréscimo do conteúdo calórico destes pães.

O pão é composto basicamente de farinha de trigo, água, fermento biológico e sal (cloreto de sódio). Entretanto, outros componentes são adicionados em pequenas quantidades para melhorar as características da massa durante o processamento e a qualidade do produto final. Estes componentes podem ser gorduras vegetais, açúcares, emulsificantes, agentes oxidantes e enzimas (MATUDA, 2004).

Dentre os aditivos alimentares utilizados em panificação, os emulsificantes constituem um grupo extremamente importante, pois são responsáveis por uma série de benefícios, que vão desde a maior facilidade de manipulação das massas, até incrementos em volume e vida de prateleira dos produtos finais (KOKELAAR; GARRITSEN; PRINS, 1995; RIBOTTA et al., 2004). Os emulsificantes são categorizados em duas classes: i) os que formam complexos com o amido, favorecendo a maciez do miolo e prevenindo o envelhecimento, como por exemplo, os monoglicerídeos; e ii) os que atuam interagindo com as proteínas, fortalecendo a massa pelo aumento da capacidade do glúten de formar um filme que retém a produção de gás pela levedura, como por exemplo, o SSL (estearoil-2-lactil lactato de sódio) e o DATEM (ésteres de ácido diacetil tartárico de mono e diglicerídeos) (GÓMEZ et al., 2004; MATUDA, 2004; STAMPFLI; NERSTEN, 1995; TAMSTORF; JONSSON; KROG, 1987).

Monoglicerídeos são as substâncias emulsificantes mais empregadas nas indústrias de alimentos, cosméticos e fármacos (BORNSCHEUER, 1995). No setor de panificação, são os principais amaciadores que se complexam com a amilose, dificultando sua recristalização (retrogradação) e a perda de água liberada neste processo (STAMPFLI; NERSTEN, 1995).

Nos últimos anos, o estilo de vida saudável vem direcionando a vida de um número cada vez maior de pessoas. Este novo estilo de vida inclui, principalmente, uma alimentação baseada em produtos que não comprometam a saúde ou até promovam benefícios à mesma. Com isso, uma grande tendência é a preferência por alimentos, ingredientes e aditivos naturais (MELO, 2004).

Com o aumento da demanda por alimentos naturais, as indústrias estão pesquisando novos métodos para a obtenção de melhoria das características como maciez, textura e maior shelf-life dos pães, geralmente obtidas com a utilização de aditivos químicos (LAD; MULLINS, 1993). Nesse contexto, coadjuvantes tecnológicos "naturais", que não foram produzidos por síntese química, como as enzimas, vêm sendo cada vez mais utilizados (HAROS; ROSELL; BENEDITO, 2002; NÉRON et al., 2004).

As enzimas são empregadas na produção de diversos produtos e ingredientes alimentícios. Em panificação são utilizadas como componentes de melhoradores ou condicionadores de massas.

As enzimas mais utilizadas em panificação são as amilases (GIMÉNEZ et al., 2007; HAROS; ROSELL; BENEDITO, 2002; LEÓN; DURÁN; BARBER, 2002). Além das amilases, recentemente vêm sendo introduzidas novas enzimas na tecnologia de panificação, dentre as quais podemos destacar as hemicelulases, as glicose-oxidases, as xilanases, as lipases e as proteases (VAN DER MAAREL et al., 2002).

A adição das enzimas em panificação tem como objetivo melhorar as características reológicas da massa, atuando nas moléculas do amido ou das proteínas, aumentando o volume do pão, a vida útil e melhorando a estrutura do miolo (HASAN; SHAH; HAMEED, 2006; POUTANEN, 1997).

As lipases, também denominadas triacilglicerol éster hidrolases (EC 3.1.1.3), catalisam a hidrólise de óleos e gorduras liberando ácidos graxos livres, diglicerídeos, monoglicerídeos e glicerol (BEISSON et al., 2000; CARVALHO et al., 2003; HASAN; SHAH; HAMEED, 2006). Encontram-se largamente distribuídas na natureza em animais, vegetais e microrganismos. As lipases provenientes de microrganismos são as mais utilizadas industrialmente, porque além de apresentarem procedimentos mais simples de isolamento, a partir do caldo fermentativo, são geralmente mais estáveis que as enzimas de outras origens e com propriedades bem mais diversificadas que as lipases de outras fontes (CAMPOS et al., 2002).

Devido à grande variedade de reações que catalisam, as lipases têm inúmeras aplicações nas indústrias de alimentos, cosméticos, química, farmacêutica e em muitas outras (HOUDE; KADEMI; LEBLANC, 2004). Têm sido raramente empregadas em panificação, devido ao efeito prejudicial observado pela ação das lipases endógenas, que liberam ácidos graxos insaturados (PYLER, 1988; TAIT; GALLIARD, 1988). As lipases podem produzir mono e diglicerídeos provenientes da adição de lipídeos, melhorando o volume específico, maciez do miolo e, conseqüentemente, retardando o envelhecimento dos pães (GIL et al., 1999). Além disso, as enzimas lipases proporcionam aumento da elasticidade e fortalecimento da massa (GOESAERT et al., 2005).

León, Durán e Barber (2002) estudaram a influência de misturas de enzimas contendo $\alpha$-amilase e lipase em formulações de pães e verificaram um efeito benéfico na manutenção das propriedades sensoriais, na firmeza e na formação do complexo amilose-lipídico termoestável, responsável por retardar a retrogradação. Segundo Gandhi (1997), a adição de lipases em pães e bolos aumenta a capacidade de retenção de ar e o aroma.

A adição de lipases pode produzir pequenas quantidades de ácidos graxos livres de cadeia curta, que influenciam o aroma do pão. Entretanto, em massas ácidas, a eficiência da lipase pode ser afetada devido ao baixo $\mathrm{pH}$ decorrente da fermentação láctica. Muitas lipases, dependendo de sua fonte, apresentam atividade ótima em $\mathrm{pH}$ próximo à neutralidade (GALAL; JOHNSON; VARRIANO-MARSTON, 1978).

No presente trabalho, foi verificada a possibilidade de substituição do emulsificante monoglicerídeo pela enzima lipase em formulação de pão de forma enriquecido com fibras para a manutenção das características de umidade e maciez durante o shelf-life. 


\section{Material e métodos}

\subsection{Matérias-primas}

A farinha de trigo (Braswey S/A Ind. e Com.) e o farelo de trigo (Alkibs Farinhas Integrais), utilizados neste trabalho, foram gentilmente cedidos pelos fornecedores. Além disto, foram utilizadas as seguintes matérias-primas: gordura vegetal hidrogenada HB40 (Triângulo Alimentos Ltda.); propionato de cálcio aglomerado (Metachem Ind. Com. Ltda.) e ácido ascórbico (vitamina C) (BASF S/A). As enzimas $\alpha$-amilase PANZYN ${ }^{\circledR}$ FA100 e lipase MONOMAX ${ }^{\circledast}$ foram gentilmente cedidas pela Prozyn Ind. Com. Ltda. Segundo informação do fabricante, a enzima lipase apresenta atividade enzimática mínima de $2.584 \mathrm{PLU}_{\mathrm{g}}{ }^{-1} \mathrm{e}$ atuação ótima à temperatura de $37^{\circ} \mathrm{C} \mathrm{e} \mathrm{pH} \mathrm{7,5.} \mathrm{O} \mathrm{emulsificante}$ monoglicerídeo destilado DIMODAN ${ }^{\circledR}$ PH200 VEG foi gentilmente cedido pela Danisco Brasil Ltda., e segundo o fabricante, possui as seguintes especificações físico-químicas: mínimo de $90 \%$ de monoglicerídeos totais; máximo de 1\% de glicerol livre; e índice de acidez máximo igual a $3 \mathrm{mg} \mathrm{KOH} \cdot \mathrm{g}^{-1}$. As demais matérias-primas foram adquiridas no comércio local.

\section{Caracterização das matérias-primas \\ (farinha de trigo e farelo de trigo)}

Foi determinada a composição centesimal: umidade (em triplicata), de acordo com o método AACC 44-15A (1995); proteína bruta (em triplicata), de acordo com o método AACC 46-13 (1995); lipídeos (em triplicata), pela metodologia proposta pelo Instituto Adolfo Lutz (1976); cinzas (em quintuplicata), de acordo com o método AACC 08-12 (1995); carboidratos totais, por diferença, e fibra bruta (em quadruplicata), pela metodologia proposta pelo Instituto Adolfo Lutz (1985). Também foi realizada a análise de distribuição do tamanho das partículas (granulometria), em duplicata, de acordo com o método 965.22 da AOAC (1995), utilizando-se peneiras de 32, 65, 80, 100 e 150 mesh para a farinha, e de $10,20,28,32$ e 80 mesh para o farelo. A utilização de seqüências diferentes de peneiras ocorreu em função da grande diferença de granulometria entre a farinha e o farelo.

A absorção de água e as propriedades reológicas da massa foram determinadas (em duplicata) para a farinha de trigo e para a mistura de farinha e farelo de trigo (80:20) com o auxílio do farinógrafo Brabender, de acordo com o método AACC 54-21 (1995). Os parâmetros obtidos a partir do farinograma foram: i) absorção de água; ii) tempo de desenvolvimento da massa; iii) estabilidade; e iv) índice de tolerância à mistura. Também foram determinadas as propriedades reológicas da massa de farinha e da mistura de farinha e farelo de trigo (80:20) com o auxílio do extensógrafo Brabender, em duplicata, segundo o método AACC 54-10 (1995). Os parâmetros obtidos a partir do extensograma foram: i) resistência à extensão ou elasticidade $(\mathrm{R})$; ii) resistência máxima $\left(\mathrm{R}_{\mathrm{m}}\right)$; iii) extensibilidade $(\mathrm{E})$; e iv) número proporcional (D).

\subsection{Delineamento experimental}

A análise do efeito combinado das variáveis individuais sobre as características tecnológicas do pão de forma foi realizada utilizando-se um delineamento experimental fatorial completo, do tipo composto central rotacional, envolvendo 2 variáveis independentes (adição de lipase e adição de monoglicerídeo). A Tabela 1 apresenta os níveis das variáveis independentes, compreendendo os pontos inferior $(-1)$, superior $(+1)$, central (0) e axiais $(+\alpha$ e $-\alpha)$.

A matriz do delineamento experimental aplicado é apresentada na Tabela 2. Foram realizados 12 ensaios, sendo quatro fatoriais (combinações dos níveis $-1 \mathrm{e}+1$ ), quatro axiais $(-\alpha$ e $+\alpha)$ e quatro repetições no ponto central (0). Os ensaios foram efetuados em ordem aleatória, segundo o procedimento determinado por Barros Neto, Scarminio e Bruns (1996).

Paralelamente aos ensaios realizados segundo o delineamento experimental descrito, foram produzidos pães com uma formulação controle, sem a adição do emulsificante monoglicerídeo e da enzima lipase, para comparação das propriedades dos pães produzidos com as diferentes formulações, com e sem os aditivos e/ou coadjuvantes.

\subsection{Preparo dos pães}

Para o preparo dos pães, utilizou-se a formulação proposta por Almeida (2006), com pequenas modificações (Tabela 3).

Os pães de forma foram produzidos na planta piloto de panificação do Departamento de Tecnologia de Alimentos (DTA), da Faculdade de Engenharia de Alimentos (FEA), da Universidade Estadual de Campinas (UNICAMP). O preparo dos pães de forma consistiu na adição dos ingredientes na amassadeira HYPPOLITO automática espiral HAE10, homogeneização na velocidade lenta, e adição, aos poucos, de água gelada. Os ingredientes foram misturados na velocidade rápida para a formação da massa (até atingir o ponto de véu). Realizou-

Tabela 1. Variáveis e níveis do delineamento experimental fatorial completo $2^{2}$ para os pães de forma.

\begin{tabular}{lccccc}
\hline Variável independente & \multicolumn{5}{c}{ Nível de variação } \\
\cline { 2 - 6 } & $-\alpha$ & -1 & 0 & +1 & $+\alpha$ \\
\hline Lipase $(\mathrm{ppm})^{*}$ & 0 & 7 & 25 & 43 & 50 \\
Monoglicerídeo $(\%)^{*}$ & 0 & 0,3 & 1 & 1,7 & 2 \\
\hline
\end{tabular}

${ }^{\star}$ Dosagens sobre a $\%$ de farinha e farelo.

Tabela 2. Matriz do delineamento experimental fatorial completo $2^{2}$.

\begin{tabular}{cccccc}
\hline \multirow{2}{*}{ Ensaio } & \multicolumn{2}{c}{ Lipase } & & \multicolumn{2}{c}{ Monoglicerídeo } \\
\cline { 2 - 3 } \cline { 5 - 6 } 1 & Codificado & Real $(\mathrm{ppm})^{*}$ & & Codificado & Real $(\%)^{*}$ \\
2 & -1 & 7 & -1 & 0,3 \\
3 & +1 & 43 & -1 & 0,3 \\
4 & -1 & 7 & +1 & 1,7 \\
5 & +1 & 43 & +1 & 1,7 \\
6 & $-\alpha$ & 0 & 0 & 1 \\
7 & $+\alpha$ & 50 & 0 & 1 \\
8 & 0 & 25 & $-\alpha$ & 0 \\
$9(\mathrm{C})$ & 0 & 25 & $+\alpha$ & 2 \\
$10(\mathrm{C})$ & 0 & 25 & 0 & 1 \\
$11(\mathrm{C})$ & 0 & 25 & 0 & 1 \\
$12(\mathrm{C})$ & 0 & 25 & 0 & 1
\end{tabular}

${ }^{*}$ Dosagens sobre a \% de farinha e farelo; e (C): ponto central. 
Tabela 3. Formulação dos pães de forma.

\begin{tabular}{lc}
\hline \multicolumn{1}{c}{ Ingrediente } & Quantidade $^{*}$ \\
\hline Farinha de trigo & $80 \%$ \\
Farelo de trigo & $20 \%$ \\
Sal refinado iodado & $1,5 \%$ \\
Açúcar cristal & $4 \%$ \\
Gordura vegetal hidrogenada & $4 \%$ \\
Enzima $\alpha$-amilase & $80 \mathrm{ppm}$ \\
Coadjuvante de tecnologia ácido ascórbico & $100 \mathrm{ppm}$ \\
Conservante propionato de cálcio & $0,2 \%$ \\
Fermento biológico instantâneo & $1,7 \%$ \\
Água & $64,6 \%$ \\
Emulsificante monoglicerídeo & $0-2 \%$ \\
Enzima lipase & $0-50 \mathrm{ppm}$ \\
\hline *Dosagens sobre a \% de farinha e farelo; e ${ }^{* *}$ Absorção farinográica.
\end{tabular}

se o descanso da massa por aproximadamente 10 minutos, e posteriormente, a divisão em partes de $450 \mathrm{~g}$. A modeladora HYPPOLITO auxiliou na modelagem dos pães, que foram em seguida colocados em formas de folha galvanizada de ferro $(22 \times 11 \mathrm{~cm})$ e em câmara de fermentação MAQUIP, por 1 hora e 40 minutos. O forneamento foi realizado em Mini Forno HYPO, a $160^{\circ} \mathrm{C}$ por 40 minutos, e após 1 hora de resfriamento, os pães foram fatiados, embalados em sacos plásticos e armazenados à temperatura ambiente até a realização das análises.

Os seguintes parâmetros foram controlados e registrados durante o processo de preparo dos pães: temperatura ambiente, temperatura da água, tempo de mistura, temperatura da massa após a mistura, temperatura inicial e final da câmara de fermentação.

\subsection{Avaliação dos pães}

Os pães foram avaliados quanto à umidade e firmeza no primeiro, quarto e sétimo dias após o preparo. Também foram avaliados o volume específico e a aceitação sensorial, após 1 dia do processamento dos pães.

\section{Volume especifico}

O volume específico foi determinado pelo método de deslocamento de sementes de painço, conforme descrito por Almeida (2006). A análise foi efetuada em quadruplicata.

\section{Umidade durante o armazenamento}

A determinação da umidade dos pães foi efetuada, em triplicata, por dessecação, em temperatura ambiente por 24 horas, seguida de dessecação em estufa a $130^{\circ} \mathrm{C}$, até massa constante, de acordo com o método AACC 44-15 (1995).

\section{Firmeza dos pães durante o armazenamento}

A firmeza dos pães, expressa pela força máxima aplicada para pressionar duas fatias centrais de pão de forma $(5 \mathrm{~cm})$, foi avaliada instrumentalmente utilizando-se texturômetro TA-XT2, de acordo com o método AACC 74-09 (1995). Os resultados apresentados são a média de seis repetições. As condições empregadas foram: sonda P/35; modo: força de compressão: $20 \mathrm{~g}$; velocidade de teste: $1,7 \mathrm{~mm} / \mathrm{s} ; 40 \%$ de compressão da amostra; velocidade de pré-teste: $1,0 \mathrm{~mm} / \mathrm{s}$ e velocidade de pós-teste: $3,0 \mathrm{~mm} / \mathrm{s}$. O método recomenda usar a sonda $\mathrm{P} / 36 \mathrm{R}$, mas utilizou-se a sonda $\mathrm{P} / 35$, disponível e de dimensões próximas. Isto poderia ocasionar pequenas diferenças nos resultados, na reprodução do estudo.

\section{Avaliação sensorial}

As treze amostras de pães de forma (ensaios e teste controle) foram submetidas ao teste de aceitação, utilizando-se uma escala hedônica estruturada de 9 pontos (desgostei muitíssimo $=1 \mathrm{e}$ gostei muitíssimo $=9$ ), para avaliar os atributos aparência, textura, sabor e aroma. O painel sensorial foi composto por 32 provadores não treinados, recrutados entre alunos e funcionários da Faculdade de Engenharia de Alimentos da UNICAMP, com faixa etária variando entre 18 e 40 anos. Os testes foram conduzidos em cabines individuais e as amostras foram apresentadas de forma monádica e com códigos de três números aleatórios. Os provadores também foram questionados quanto ao hábito e freqüência de consumo de pão de forma com fibras.

\section{Resultados e discussão}

\subsection{Caracterização das matérias-primas}

Os resultados obtidos para a composição centesimal da farinha de trigo foram: $13,61 \%$ umidade, $10,96 \%$ proteínas, $1,53 \%$ lipídeos, $0,32 \%$ cinzas e $73,68 \%$ carboidratos (sendo 3,4\% fibra bruta). Estes dados apontam que a mesma apresenta um elevado teor de carboidratos e baixo teor de fibra bruta. Os resultados encontrados para a farinha de trigo são próximos aos relatados por Turola (2002).

O farelo de trigo apresentou a seguinte composição: 11,23\% umidade, $15,55 \%$ proteínas, $4,29 \%$ lipídeos, $5,78 \%$ cinzas e $63,15 \%$ carboidratos (sendo $46,31 \%$ fibra bruta). Observa-se a grande quantidade de fibra bruta, fato que justifica a utilização do mesmo como ingrediente no desenvolvimento de pão de forma com alto teor de fibras; além de um teor protéico significativo. A composição centesimal do farelo de trigo é muito próxima à reportada por Ferreira (2006).

A farinha de trigo apresentou granulometria predominantemente entre 106 e $210 \mu \mathrm{m}$ (84,64\% de suas partículas). O farelo de trigo apresentou partículas maiores, sendo que $79,96 \%$ das partículas apresentaram tamanho superior a $600 \mu \mathrm{m}$.

Analisando os resultados apresentados na Tabela 4, pode-se afirmar que a farinha de trigo apresentou características de uma farinha muito forte (BIONDI, 2003). Isto é um dado importante, pois o glúten presente na farinha foi posteriormente diluído com a adição de farelo de trigo. Geralmente, farinhas muito fortes são utilizadas em misturas com outras mais fracas. Os dados obtidos no farinograma estão de acordo com os estudos de Al-Eid, Al-Neshawy e Al-Shaikh Ahmad (1999). Verificouse que a adição de farelo de trigo à massa, na proporção de $20 \%$ (Tabela 4), aumentou a absorção de água, o tempo de 
Lipase e monoglicerídeo em pão

Tabela 4. Características reológicas da farinha de trigo e da mistura farinha e farelo.

\begin{tabular}{|c|c|c|}
\hline & $\begin{array}{l}\text { Farinha de } \\
\quad \text { trigo }\end{array}$ & $\begin{array}{c}\text { Farinha e } \\
\text { farelo de } \\
\text { trigo }^{*}\end{array}$ \\
\hline \multicolumn{3}{|l|}{ Farinografia: } \\
\hline Absorção de água (\%) & $59,1 \pm 0,4$ & $64,5 \pm 0,5$ \\
\hline Tempo de desenvolvimento (minutos) & $14,5 \pm 0,2$ & $16 \pm 0,3$ \\
\hline Estabilidade à mistura (minutos) & $19 \pm 0,3$ & $8 \pm 0,2$ \\
\hline Índice de tolerância à mistura (UF) & $10 \pm 0,5$ & $20 \pm 1,5$ \\
\hline \multicolumn{3}{|l|}{ Extensografia: } \\
\hline Tempo de 45 minutos: R (UE) & $480 \pm 4$ & $725 \pm 11$ \\
\hline $\mathrm{R}_{\mathrm{m}}(\mathrm{UE})$ & $650 \pm 6$ & $725 \pm 11$ \\
\hline $\mathrm{E}(\mathrm{mm})$ & $137 \pm 1$ & $70 \pm 1$ \\
\hline $\mathrm{D}(\mathrm{UE}) / \mathrm{mm}$ & $4,7 \pm 0,1$ & $10,4 \pm 0,2$ \\
\hline Tempo de 90 minutos: R (UE) & $610 \pm 5$ & $>1000$ \\
\hline $\mathrm{R}_{\mathrm{m}}(\mathrm{UE})$ & $800 \pm 8$ & $>1000$ \\
\hline $\mathrm{E}(\mathrm{mm})$ & $125 \pm 1$ & $70 \pm 1$ \\
\hline $\mathrm{D}(\mathrm{UE}) / \mathrm{mm}$ & $6,4 \pm 0,2$ & $>14,3$ \\
\hline Tempo de 135 minutos: R (UE) & $580 \pm 5$ & $>1000$ \\
\hline $\mathrm{R}_{\mathrm{m}}(\mathrm{UE})$ & $690 \pm 9$ & $>1000$ \\
\hline $\mathrm{E}(\mathrm{mm})$ & $127 \pm 2$ & $76 \pm 2$ \\
\hline $\mathrm{D}(\mathrm{UE}) / \mathrm{mm}$ & $5,4 \pm 0,1$ & $>13,2$ \\
\hline
\end{tabular}

${ }^{*}$ Proporção: $80 \%$ farinha $+20 \%$ farelo; UF: unidades farinográficas; UE: unidades extensográficas; R: resistência à extensão ou elasticidade; Rm: resistência máxima; E: extensibilidade; e D: número proporcional.

desenvolvimento e o índice de tolerância à mistura, e reduziu a estabilidade à mistura.

Os resultados extensográficos mostram que a farinha de trigo e a mistura de farinha e farelo de trigo apresentaram resultados de uma massa muito rígida e curta, com baixa extensibilidade e alta resistência à extensão. Observou-se que a adição de farelo de trigo à massa, na proporção de $20 \%$, aumentou a elasticidade/resistência à extensão $\left(\mathrm{R}\right.$ e $\left.\mathrm{R}_{\mathrm{m}}\right)$, diminuiu a extensibilidade (E) e, conseqüentemente, aumentou o número proporcional (D).

\subsection{Avaliação dos pães}

\section{Volume específico}

A Tabela 5 apresenta os valores médios de volume específico dos pães de forma enriquecidos com fibras.

Os pães, com peso de aproximadamente $450 \mathrm{~g}$, apresentaram volume específico entre 3,77 e $4,40 \mathrm{~cm}^{3} \cdot \mathrm{g}^{-1}$. O pão controle, sem adição de lipase e monoglicerídeo, apresentou volume específico de $4,17 \mathrm{~cm}^{3} \cdot \mathrm{g}^{-1}$, resultado próximo aos valores encontrados nos testes. É sabido que a adição de glúten, agentes oxidantes, alguns emulsificantes e enzimas melhoram a retenção dos gases, e conseqüentemente, o volume final. Por outro lado, a adição de outros cereais, como a farinha de rosca e os farelos, têm ação deletéria sobre a massa, ocasionando a redução do volume (ESTELLER, 2004).

Os resultados obtidos foram similares aos encontrados por Katina et al. (2006) e por Bonet et al. (2006). Katina et al. (2006)
Tabela 5. Influência da adição de lipase e monoglicerídeo sobre o volume dos pães.

\begin{tabular}{cccc}
\hline Ensaio & Lipase $(\mathrm{ppm})$ & Monoglicerídeo $(\%)$ & Volume $\left(\mathrm{cm}^{3} \cdot \mathrm{g}^{-1}\right)$ \\
\hline 1 & 7 & 0,3 & $3,86 \pm 0,15$ \\
2 & 43 & 0,3 & $4,08 \pm 0,08$ \\
3 & 7 & 1,7 & $3,77 \pm 0,06$ \\
4 & 43 & 1,7 & $3,96 \pm 0,08$ \\
5 & 0 & 1 & $4,34 \pm 0,17$ \\
6 & 50 & 1 & $4,22 \pm 0,16$ \\
7 & 25 & 0 & $3,79 \pm 0,12$ \\
8 & 25 & 2 & $4,19 \pm 0,07$ \\
$9(\mathrm{C})$ & 25 & 1 & $4,05 \pm 0,24$ \\
$10(\mathrm{C})$ & 25 & 1 & $4,12 \pm 0,08$ \\
$11(\mathrm{C})$ & 25 & 1 & $4,40 \pm 0,03$ \\
$12(\mathrm{C})$ & 25 & 1 & $4,13 \pm 0,07$ \\
Controle & 0 & 0 & $4,17 \pm 0,07$ \\
\hline
\end{tabular}

(C): ponto central.

apresentaram valor de $4,1 \mathrm{~cm}^{3} \cdot \mathrm{g}^{-1}$ para o volume específico de pães de forma com alto teor de fibras e com adição de misturas de enzimas contendo $\alpha$-amilase, xilanase e lipase. Bonet et al. (2006) relataram volumes específicos variando de 3,41 a $4,42 \mathrm{~cm}^{3} \cdot \mathrm{g}^{-1}$, dependendo da concentração da enzima glicose oxidase adicionada à massa de pães.

Verificou-se que nenhuma das variáveis independentes (adição de lipase ou adição de monoglicerídeo) apresentou efeito significativo $(\mathrm{p}<0,10)$ sobre o volume dos pães. Portanto, dentro das condições estudadas, não foi possível estabelecer um modelo matemático para o volume dos pães.

\section{Umidade durante o armazenamento}

De acordo com a Tabela 6, após 1 dia do processamento dos pães, foram encontrados valores de umidade entre 33,97 e $37,69 \%$. Nos pães elaborados com a formulação controle, foram obtidos valores médios de umidade de 34,13\%.

Os teores de umidade apresentados pelos pães de forma enriquecidos com fibras foram menores que os reportados por Pontes (2006). Em um estudo sobre o desenvolvimento de pão de forma sem a adição de açúcares, gorduras e emulsificantes, a autora avaliou a vida de prateleira de pães preparados pelo método de massa direta e relatou teores de umidade variando de 43,02 a 45,14\%, dependendo dos teores de enzima fosfolipase, enzima amiloglucosidase e amido modificado e pré-gelatinizado de mandioca, utilizados nas formulações.

Após 4 dias do processamento, todos os pães apresentaram uma redução no teor de umidade, com valores entre 33,58 e $36,26 \%$. Os pães da formulação controle também apresentaram uma redução no teor de umidade, com valor médio de 32,91\%, inferior aos valores encontrados nos ensaios (Tabela 6). Porém, a redução da umidade foi mais acentuada após 7 dias do processamento, sendo encontrados valores entre 32,02 e $34,69 \%$. Os valores médios da formulação controle também mantiveram a tendência de redução, com 31,55\%, inferior aos valores encontrados nos ensaios (Tabela 6). 
Nenhuma das variáveis independentes (adição de lipase ou adição de monoglicerídeo) apresentou efeito significativo $(\mathrm{p}<0,10)$ sobre os valores de umidade registrados no dia $1 \mathrm{de}$ análise. Portanto, dentro das condições estudadas, não foi possível estabelecer um modelo matemático para o teor de umidade dos pães neste dia. Já para os valores de umidade registrados no $4^{\text {o e }} 7^{\circ}$ dia, foi possível verificar o efeito significativo $(p<0,10)$ das variáveis, possibilitando estabelecer um modelo matemático (para uso com as variáveis codificadas) dentro das condições estudadas.

Modelo para umidade ( $\left.4^{\circ} \mathrm{dia}\right)$ :

$$
\begin{aligned}
y= & 34,02-0,36 x_{1}+0,23 x_{2}+0,67 x_{2}^{2}-0,42 x_{1} x_{2} \\
& \text { Modelo para umidade }\left(7^{o} \text { dia }\right):
\end{aligned}
$$$$
y=33,01-0,43 x_{1}+0,24 x_{1}^{2}+0,56 x_{2}^{2}-0,68 x_{1} x_{2}
$$

em que: $\mathbf{x}_{1}=$ lipase e $\mathbf{x}_{2}=$ monoglicerídeo.

A validade dos modelos para a umidade no $4^{\circ}$ e $7^{\circ}$ dia foi verificada pela análise de variância (ANOVA). Obtiveram-se valores de $\mathrm{R}^{2}=0,6965$ ( $4^{\circ} \mathrm{dia}$ ) e $\mathrm{R}^{2}=0,7206$ ( $7^{\circ} \mathrm{dia}$ ). Embora o $\mathrm{F}$ calculado tenha sido apenas 1,4 e 1,5 vezes maior que o F tabelado, para a umidade do $4^{\circ}$ e $7^{\circ}$ dia, respectivamente, os desvios entre os valores obtidos experimentalmente e os valores preditos pelo modelo (Tabela 7) são muito pequenos (máximo -2,39\%), demonstrando que o modelo obtido é adequado para estimar o teor de umidade em função das dosagens de lipase e de monoglicerídeo.

Na Figura 1, são apresentadas as superfícies de resposta da variação do teor de umidade dos pães de forma em função das concentrações de enzima lipase e emulsificante monoglicerídeo, após 4 e 7 dias de armazenamento. Observou-se que as superfícies do $4^{\circ}$ e $7^{\circ}$ dia apresentaram comportamento semelhante, evidenciando, em primeiro lugar, que pães de forma com maior porcentagem de monoglicerídeo e menor concentração de lipase apresentaram maior teor de umidade. Entretanto, existe outra região de umidade máxima, quando níveis mais baixos de mo- noglicerídeo são utilizados e o aumento da dosagem de lipase parece ter efeito positivo sobre a retenção da umidade.

\section{Firmeza durante o armazenamento}

A Tabela 8 mostra os valores de firmeza dos pães nos dias 1, 4 e 7, mostrando que há concordância com a literatura (BONET et al., 2006; GIL et al., 1999; KATINA et al., 2006; SAHLSTRÖM; BRATHEN, 1997), onde se afirma que devido às transformações ocorridas nos ingredientes e, principalmente, à retrogradação do amido, ocorre redução na maciez do miolo dos pães e aumento na força de compressão com o decorrer da vida de prateleira. Observa-se que os valores de firmeza variaram de 955,94 a 2073,91 g durante o tempo de armazenamento dos pães de forma. Para os pães do teste controle, observou-se uma faixa de firmeza de 1355,6 a 2190,82 g, valores superiores aos encontrados nos ensaios.

Lima, Guraya e Champagne (2002) relataram um aumento significativo na firmeza de pães de forma, cortados em cubos, preparados com adição de farelo de arroz em substituição parcial à farinha de trigo, em concentrações de 10 e $20 \%$, em relação a um controle sem farelo. Haros, Rosell e Benedito (2002) observaram que a adição de carbohidrases (celulase, xilanase e $\beta$-glucanase) em pão de forma, quando comparado com um controle, reduziu a firmeza das amostras em até $29 \%$ durante 6 dias de armazenamento.

Nenhuma das variáveis independentes (adição de lipase ou adição de monoglicerídeo) apresentou efeito significativo $(\mathrm{p}<0,10)$ sobre a firmeza nos dias 1, 4 ou 7. Portanto, dentro das condições estudadas, não foi possível estabelecer modelos matemáticos para a firmeza dos pães.

\section{Avaliação sensorial}

A Tabela 9 mostra as médias de aceitação dos pães de forma em relação aos atributos sensoriais aparência, textura, sabor e aroma. Observa-se que os valores médios para estes atributos situaram-se entre 6,53 e 7,78, ou seja, os provadores classificaram os pães enriquecidos com fibras entre "gostei ligeiramente"

\begin{tabular}{|c|c|c|c|c|c|}
\hline Ensaio & Lipase (ppm) & Monoglicerídeo (\%) & $\begin{array}{l}\text { Umidade } \\
1^{\circ} \text { dia }(\%)\end{array}$ & $\begin{array}{l}\text { Umidade } \\
4^{\circ} \text { dia }(\%)\end{array}$ & $\begin{array}{c}\text { Umidade } \\
7^{\circ} \text { dia (\%) }\end{array}$ \\
\hline 1 & 7 & 0,3 & $36,15 \pm 0,35$ & $35,12 \pm 0,11$ & $34,35 \pm 0,29$ \\
\hline 2 & 43 & 0,3 & $36,22 \pm 0,61$ & $35,01 \pm 0,12$ & $34,39 \pm 0,29$ \\
\hline 3 & 7 & 1,7 & $36,36 \pm 0,36$ & $35,43 \pm 0,20$ & $34,69 \pm 0,25$ \\
\hline 4 & 43 & 1,7 & $34,75 \pm 0,14$ & $33,64 \pm 0,33$ & $32,02 \pm 0,24$ \\
\hline 5 & 0 & 1 & $35,50 \pm 0,18$ & $34,30 \pm 0,27$ & $33,69 \pm 0,32$ \\
\hline 6 & 50 & 1 & $33,97 \pm 0,45$ & $33,58 \pm 0,07$ & $33,14 \pm 0,08$ \\
\hline 7 & 25 & 0 & $35,10 \pm 0,42$ & $34,21 \pm 0,25$ & $33,55 \pm 0,22$ \\
\hline 8 & 25 & 2 & $37,69 \pm 0,54$ & $36,26 \pm 0,39$ & $34,55 \pm 0,27$ \\
\hline $9(\mathrm{C})$ & 25 & 1 & $34,62 \pm 0,30$ & $33,83 \pm 0,25$ & $32,88 \pm 0,74$ \\
\hline $10(\mathrm{C})$ & 25 & 1 & $35,48 \pm 0,33$ & $34,11 \pm 0,14$ & $33,04 \pm 0,59$ \\
\hline $11(\mathrm{C})$ & 25 & 1 & $35,06 \pm 0,21$ & $34,19 \pm 0,43$ & $33,24 \pm 0,48$ \\
\hline $12(\mathrm{C})$ & 25 & 1 & $34,49 \pm 0,29$ & $33,89 \pm 0,11$ & $32,87 \pm 0,58$ \\
\hline Controle & 0 & 0 & $34,13 \pm 0,22$ & $32,91 \pm 0,22$ & $31,55 \pm 0,41$ \\
\hline
\end{tabular}

Tabela 6. Influência da adição de lipase e monoglicerídeo na umidade dos pães durante o armazenamento.

(C): ponto central. 
Umidade $4^{\circ}$ dia

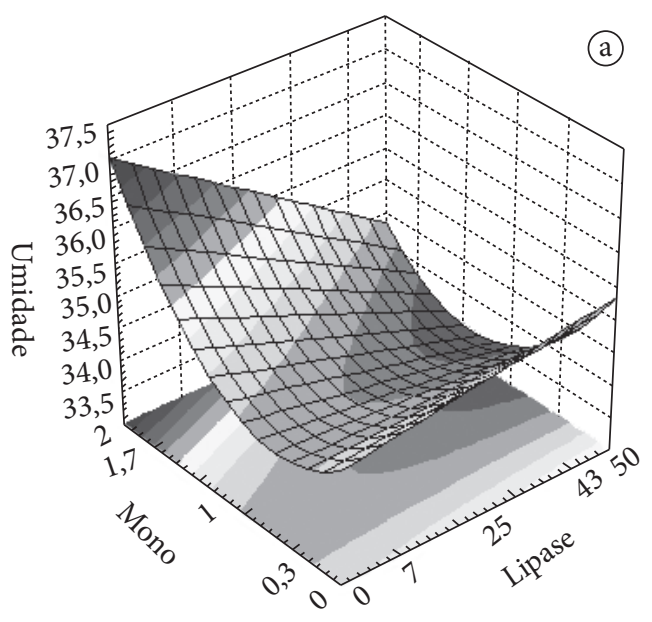

Umidade $7^{\circ}$ dia

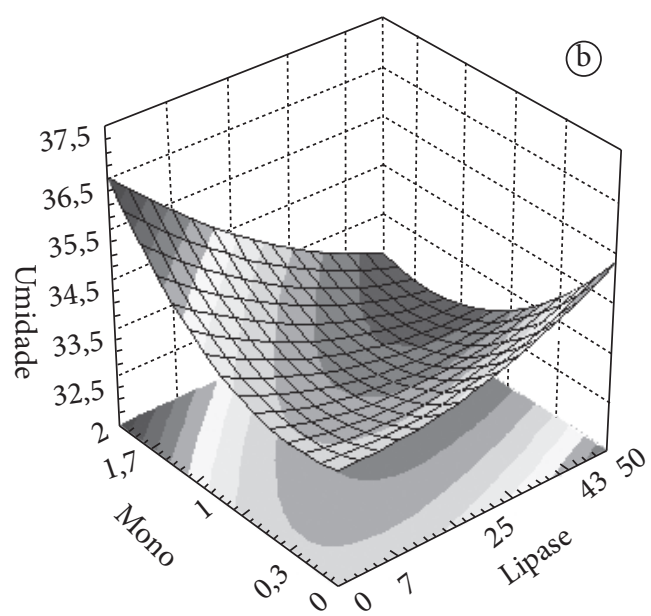

Figura 1. a) Variação do teor de umidade dos pães de forma em função das concentrações de enzima lipase e emulsificante monoglicerídeo após 4 ; e b) 7 dias de armazenamento.

Tabela 7. Comparação entre os valores obtidos experimentalmente e os valores preditos pelo modelo.

\begin{tabular}{|c|c|c|c|c|c|c|c|c|}
\hline \multirow[t]{2}{*}{ Ensaio } & \multirow[t]{2}{*}{ Lipase } & \multirow[t]{2}{*}{ Monoglicerídeo } & \multicolumn{3}{|c|}{ Umidade $4^{\circ}$ dia } & \multicolumn{3}{|c|}{ Umidade $7^{\circ}$ dia } \\
\hline & & & $\operatorname{EXP}(\%)$ & PRED (\%) & Desvio (\%) & $\operatorname{EXP}(\%)$ & PRED (\%) & Desvio (\%) \\
\hline 1 & -1 & -1 & 35,12 & 34,40 & 2,05 & 34,35 & 33,56 & 2,30 \\
\hline 2 & 1 & -1 & 35,01 & 34,52 & 1,40 & 34,39 & 34,06 & 0,96 \\
\hline 4 & 1 & 1 & 33,64 & 34,14 & $-1,49$ & 32,02 & 32,70 & $-2,12$ \\
\hline 5 & $-1,41$ & 0 & 34,30 & 34,53 & $-0,66$ & 33,69 & 34,09 & $-1,20$ \\
\hline 8 & 0 & 1,41 & 36,26 & 35,68 & 1,61 & 34,55 & 34,12 & 1,23 \\
\hline $9(\mathrm{C})$ & 0 & 0 & 33,83 & 34,02 & $-0,56$ & 32,88 & 33,01 & $-0,40$ \\
\hline $10(\mathrm{C})$ & 0 & 0 & 34,11 & 34,02 & 0,26 & 33,04 & 33,01 & 0,09 \\
\hline $11(\mathrm{C})$ & 0 & 0 & 34,19 & 34,02 & 0,50 & 33,24 & 33,01 & 0,69 \\
\hline $12(\mathrm{C})$ & 0 & 0 & 33,89 & 34,02 & $-0,38$ & 32,87 & 33,01 & $-0,43$ \\
\hline
\end{tabular}

EXP: valor obtido experimentalmente; PRED: valor predito pelo modelo, com uso das variáveis codificadas; e Desvio (\%) = ((EXP - PRED)/EXP)X100.

Tabela 8. Influência da adição de lipase e monoglicerídeo na firmeza do miolo dos pães durante o armazenamento.

\begin{tabular}{cccccc}
\hline Ensaio & Lipase $(\mathrm{ppm})$ & Monoglicerídeo $(\%)$ & Firmeza $1^{\circ}$ dia $(\mathrm{g})$ & Firmeza $4^{\circ}$ dia $(\mathrm{g})$ & Firmeza $7^{\circ}$ dia $(\mathrm{g})$ \\
\hline 1 & 7 & 0,3 & $1230,59 \pm 51,26$ & $1565,21 \pm 62,67$ & $1849,26 \pm 65,65$ \\
2 & 43 & 0,3 & $1260,53 \pm 63,45$ & $1730,06 \pm 119,60$ & $2073,91 \pm 192,30$ \\
3 & 7 & 1,7 & $1274,66 \pm 99,26$ & $1590,16 \pm 95,86$ & $1910,25 \pm 52,97$ \\
4 & 43 & 1,7 & $1254,68 \pm 105,12$ & $1588,73 \pm 148,00$ & $1817,04 \pm 95,27$ \\
5 & 0 & 1 & $1048,05 \pm 92,44$ & $1366,84 \pm 26,52$ & $1823,99 \pm 89,46$ \\
6 & 50 & 1 & $1187,26 \pm 84,27$ & $1566,93 \pm 141,07$ & $1956,30 \pm 192,25$ \\
7 & 25 & 0 & $1040,18 \pm 44,62$ & $1708,77 \pm 117,26$ & $1997,19 \pm 192,98$ \\
8 & 25 & 2 & $963,47 \pm 57,40$ & $1260,75 \pm 83,16$ & $1511,58 \pm 116,91$ \\
$9(\mathrm{C})$ & 25 & 1 & $1080,64 \pm 70,52$ & $1496,45 \pm 87,18$ & $1841,77 \pm 170,40$ \\
$10(\mathrm{C})$ & 25 & 1 & $956,38 \pm 65,30$ & $1279,08 \pm 73,75$ & $1658,37 \pm 159,42$ \\
$11(\mathrm{C})$ & 25 & 1 & $955,94 \pm 94,59$ & $1378,03 \pm 69,98$ & $1590,57 \pm 77,62$ \\
$12(\mathrm{C})$ & 25 & 1 & $1005,82 \pm 71,79$ & $1524,16 \pm 100,26$ & $1944,83 \pm 154,83$ \\
Controle & 0 & 0 & $1355,60 \pm 30,78$ & $1916,44 \pm 134,13$ & $2190,82 \pm 213,89$ \\
\hline
\end{tabular}

(C): ponto central. 
Tabela 9. Valores médios de aceitação para os pães de forma.

\begin{tabular}{|c|c|c|c|c|c|c|}
\hline \multirow[t]{2}{*}{ Ensaio } & \multirow{2}{*}{$\begin{array}{c}\text { Lip } \\
(\mathrm{ppm})\end{array}$} & \multirow{2}{*}{$\begin{array}{c}\text { Mono } \\
(\%)\end{array}$} & \multicolumn{4}{|c|}{ Atributos } \\
\hline & & & Aparência & Textura & Aroma & Sabor \\
\hline 1 & 7 & 0,3 & $7,50 \pm 0,79$ & $7,16 \pm 1,33$ & $7,53 \pm 0,83$ & $7,28 \pm 1,18$ \\
\hline 2 & 43 & 0,3 & $7,50 \pm 0,97$ & $7,31 \pm 1,01$ & $7,50 \pm 0,94$ & $7,53 \pm 0,87$ \\
\hline 4 & 43 & 1,7 & $7,22 \pm 1,17$ & $6,78 \pm 1,75$ & $7,41 \pm 1,25$ & $7,19 \pm 1,33$ \\
\hline 5 & 0 & 1 & $7,16 \pm 1,20$ & $6,72 \pm 1,21$ & $7,22 \pm 1,14$ & $7,19 \pm 1,16$ \\
\hline 8 & 25 & 2 & $7,69 \pm 1,10$ & $7,50 \pm 0,90$ & $7,53 \pm 1,06$ & $7,47 \pm 0,97$ \\
\hline $9(\mathrm{C})$ & 25 & 1 & $7,52 \pm 0,98$ & $7,35 \pm 1,18$ & $7,65 \pm 0,97$ & $7,52 \pm 1,27$ \\
\hline $10(\mathrm{C})$ & 25 & 1 & $7,53 \pm 0,97$ & $7,34 \pm 0,81$ & $7,56 \pm 1,06$ & $7,34 \pm 0,99$ \\
\hline $11(\mathrm{C})$ & 25 & 1 & $6,69 \pm 1,57$ & $6,78 \pm 1,43$ & $6,69 \pm 1,26$ & $6,94 \pm 1,14$ \\
\hline $12(\mathrm{C})$ & 25 & 1 & $6,94 \pm 1,12$ & $6,53 \pm 1,15$ & $6,84 \pm 1,23$ & $6,81 \pm 1,18$ \\
\hline
\end{tabular}

(C): ponto central; Lip: lipase; Mono: monoglicerídeo. Atributos avaliados em escala hedônica de 9 pontos; onde 1 = desgostei muitíssimo; e 9 = gostei muitíssimo.

e "gostei muito". Para os atributos sensoriais dos pães do teste controle, foram atribuídos valores médios de 5,31 a 6,97, ou seja, os provadores classificaram os pães do teste controle entre "nem gostei/nem desgostei" e "gostei moderadamente".

A aparência, a textura, o sabor e $\mathrm{o}$ aroma dos pães de forma receberam notas médias sensoriais de 6,69 a 7,75; 6,53 a 7,56; 6,69 a 7,78 e 6,81 a 7,59 , respectivamente. Já os pães do teste controle obtiveram para aparência, textura, sabor e aroma notas médias sensoriais de 6,22; 5,31; 6,97 e 6,91, respectivamente. Em relação aos atributos sensoriais, verifica-se que as notas médias atribuídas aos pães do teste controle foram inferiores à menor nota média dos ensaios para a aparência e a textura, mas não para o sabor e o aroma.

A textura de um alimento pode ser definida como um grupo de características físicas que provêm dos elementos estruturais do alimento (SZCZESNIAK, 2002). Essas características ou parâmetros de textura são quantificados através das análises de textura, que podem ser sensoriais ou instrumentais (ROSENTHAL, 1999). No caso de pães, a textura está relacionada com a umidade e a maciez do miolo, ou seja, com a qualidade do produto para o consumidor (CALLEJO et al., 1999), sendo este um fator imprescindível para a aceitabilidade do produto no mercado.

Nenhuma das variáveis independentes (adição de lipase ou adição de monoglicerídeo) apresentou efeito significativo $(\mathrm{p}<0,10)$ sobre a aceitação da aparência, textura, sabor e aroma. Assim, não foi possível estabelecer, dentro das condições estudadas, modelos matemáticos para os atributos sensoriais.

\subsection{Análise de variância (ANOVA)}

Como não foi possível obter modelos matemáticos para descrever os resultados de volume específico, umidade no dia 1 , firmeza nos dias 1, 4 e 7 e aceitação sensorial, foram selecionados 3 ensaios do planejamento experimental (Ensaio 5 - sem lipase; Ensaio 7 - sem monoglicerídeo; e Ensaio 9 - ponto central, com os níveis intermediários de lipase e de monoglicerídeo) e o teste controle (sem lipase e sem monoglicerídeo) para a avaliação dos dados por análise de variância.

As análises estatísticas da variância (ANOVA) foram realizadas utilizando-se o programa Statistica 5.5 (Statsoft, USA). As diferenças significativas entre as médias foram identificadas pelo teste de Tukey $(\mathrm{p}<0,05)$.

As Tabelas 10,11, 12 e 13 apresentam, respectivamente, os resultados da análise de variância para o volume específico, a umidade, a firmeza e a aceitação sensorial dos Ensaios 5, 7, 9 e teste controle.

Analisando a Tabela 10, pode-se verificar que os volumes específicos dos pães dos Ensaios 5, 7 e 9 não apresentaram diferença significativa $(\mathrm{p}<0,05)$ em relação ao grupo controle. Os pães do Ensaio 7 (25 ppm lipase) apresentaram volume específico estatisticamente inferior ao do Ensaio 5 (1\% monoglicerídeo).

Com base na análise de variância (ANOVA) (Tabela 11), observou-se que os pães do teste controle diferiram estatisticamente $(\mathrm{p}<0,05)$ dos Ensaios 5, 7 e 9 no $1^{\circ}, 4^{\circ}$ e $7^{\circ}$ dia após o forneamento, apresentando menor teor de umidade. Nos dias 4 e 7 , verifica-se também que não houve diferença significativa $(\mathrm{p}<0,05)$ entre os teores de umidade dos pães dos Ensaios 5 e 7. No $7^{\circ}$ dia após o processamento, os valores de umidade apresentados pelos pães dos Ensaios 5 e 7 foram estatisticamente superiores aos do teste controle e do Ensaio 9. Desta forma, observou-se que a enzima lipase e o emulsificante monoglicerídeo tiveram efeitos positivos na retenção de umidade durante a vida de prateleira dos pães de forma.

De acordo com a Tabela 12, após 1 e 4 dias de forneamento, os pães do teste controle apresentaram valores de firmeza significativamente superiores $(p<0,05)$ aos obtidos para os Ensaios 5,7 e 9 . Os pães dos Ensaios 5 ( $1 \%$ monoglicerídeo) e 9 ( 25 ppm lipase $+1 \%$ monoglicerídeo) foram os que apresentaram menor firmeza no $4^{\circ}$ dia, não diferindo estatisticamente $(\mathrm{p}<0,05)$ entre si. Este fato poderia indicar que este emulsificante não pode ser substituído somente por lipase. Mas no $7^{\circ}$ dia, o Ensaio 
7 (25 ppm lipase) não diferiu estatisticamente $(\mathrm{p}<0,05)$ dos Ensaios 5 e 9, nem do controle.

$\mathrm{Na}$ Tabela 13, pode-se observar que não houve diferença significativa $(p<0,05)$ entre os pães do teste controle e os Ensaios 5, 7 e 9 quanto ao atributo sabor. Em relação ao aroma, verificou-se que os melhores resultados foram para o Ensaio 7 (25 ppm lipase), apesar de não diferir dos Ensaios 5 e 9 . As notas médias atribuídas à textura das amostras dos Ensaios 5, 7 e 9 foram estatisticamente superiores às do teste controle, indicando que os pães com adição de lipase e monoglicerídeo apresentaram textura mais agradável aos consumidores. Estes dados são coerentes com os resultados obtidos para a firmeza no $1^{\circ}$ dia após o processamento, quando os pães do teste controle foram os mais duros. Os pães do teste controle também obtiveram menor aceitação em relação ao atributo aparência.

\section{Conclusões}

Com o decorrer do tempo de armazenamento, foi evidenciada a redução do teor de umidade e o conseqüente aumento da firmeza do miolo dos pães, tanto para a formulação controle, quanto para as formulações contendo lipase e monoglicerídeos. Este fenômeno de envelhecimento dos pães é causado pela retrogradação do amido.

Tabela 10. Análise de variância - volume específico.

\begin{tabular}{lccc}
\hline & Lipase (ppm) & $\begin{array}{c}\text { Monoglicerídeo } \\
(\%)\end{array}$ & $\begin{array}{c}\text { Volume Específico } \\
\left(\mathrm{cm}^{3} \cdot \mathrm{g}^{-1}\right)\end{array}$ \\
\hline Controle & 0 & 0 & $4,17 \pm 0,07^{\mathrm{ab}}$ \\
Ensaio 5 & 0 & 1 & $4,34 \pm 0,17^{\mathrm{a}}$ \\
Ensaio 7 & 25 & 0 & $3,79 \pm 0,12^{\mathrm{b}}$ \\
Ensaio 9 & 25 & 1 & $4,05 \pm 0,24^{\mathrm{ab}}$ \\
\hline
\end{tabular}

Médias seguidas da mesma letra na vertical não diferem significativamente entre si (Teste de Tukey a 95\% de significância).
Utilizando-se o planejamento experimental, modelos matemáticos foram obtidos para descrever a umidade dos pães, em função da adição de lipase e de monoglicerídeo, nos dias 4 e 7 após a produção. Maior retenção de umidade foi obtida quando se utilizou maior teor de monoglicerídeo e menor teor de lipase. Entretanto, com a redução do teor de monoglicerídeo, observou-se um efeito positivo com a adição de lipase.

$\mathrm{Na}$ análise por ANOVA, verificou-se que os pães do teste controle diferiram estatisticamente $(\mathrm{p}<0,05)$ dos Ensaios 5, 7 e 9 , apresentando valores inferiores de umidade no $4^{\circ}$ e $7^{\circ}$ dias após o processamento. Os volumes específicos dos pães dos ensaios 5, 7 e 9 não apresentaram diferença significativa $(p<0,05)$ em relação ao grupo controle. Nos dias 4 e 7 , observou-se maior efeito do emulsificante monoglicerídeo sobre a maciez do miolo do pão quando comparado à enzima lipase. Isto poderia demonstrar que em relação à maciez, o monoglicerídeo não pode ser substituído integralmente pela lipase. Entretanto, no dia 7, não se observou diferença entre os ensaios com monoglicerídeo e apenas com lipase.

$\mathrm{Na}$ avaliação sensorial foi possível verificar que as amostras do teste controle (sem lipase e sem monoglicerídeo) e dos Ensaios 5 (1\% monoglicerídeo), 7 (25 ppm lipase) e 9 ( 25 ppm lipase $+1 \%$ monoglicerídeo) não apresentaram diferença significativa somente em relação ao atributo sabor. Para os atributos aparência e textura, todos os ensaios apresentaram aceitação superior ao controle.

Nas condições em que os ensaios foram conduzidos e para as faixas de monoglicerídeo e lipase estudadas, verificou-se a possibilidade de substituir o monoglicerídeo por lipase em formulação de pão de forma enriquecido com fibras.

Uma sugestão para trabalhos futuros é a realização de testes de aceitação durante a vida de prateleira dos pães, já

Tabela 11. Análise de variância - umidade no $1^{\circ}, 4^{\circ}$ e $7^{\circ}$ dia.

\begin{tabular}{cccccc}
\hline & Lipase $(\mathrm{ppm})$ & Monoglicerídeo $(\%)$ & $1^{\mathrm{o}}$ dia & $4^{\text {o }}$ dia & $7^{\mathrm{o}}$ dia \\
\hline Controle & 0 & 0 & $34,13 \pm 0,22^{\mathrm{d}}$ & $32,91 \pm 0,22^{\mathrm{c}}$ & $31,55 \pm 0,41^{\mathrm{c}}$ \\
Ensaio 5 & 0 & 1 & $35,50 \pm 0,18^{\mathrm{a}}$ & $34,30 \pm 0,27^{\mathrm{a}}$ & $33,69 \pm 0,32^{\mathrm{a}}$ \\
Ensaio 7 & 25 & 0 & $35,10 \pm 0,42^{\mathrm{b}}$ & $34,21 \pm 0,25^{\mathrm{ab}}$ & $33,55 \pm 0,22^{\mathrm{a}}$ \\
Ensaio 9 & 25 & 1 & $34,62 \pm 0,30^{\mathrm{c}}$ & $33,83 \pm 0,25^{\mathrm{b}}$ & $32,88 \pm 0,74^{\mathrm{b}}$ \\
\hline
\end{tabular}

Médias seguidas da mesma letra na vertical não diferem significativamente entre si (Teste de Tukey a 95\% de significância).

Tabela 12. Análise de variância - firmeza no $1^{\circ}, 4^{\circ}$ e $7^{\circ}$ dia.

\begin{tabular}{cccccc}
\hline & Lipase $(\mathrm{ppm})$ & Monoglicerídeo (\%) & $1^{\mathrm{o}}$ dia & $4^{\mathrm{o}}$ dia & $7^{\mathrm{o}}$ dia \\
\hline Controle & 0 & 0 & $1355,60 \pm 30,78^{\mathrm{a}}$ & $1916,44 \pm 134,13^{\mathrm{a}}$ & $2190,82 \pm 213,89^{\mathrm{a}}$ \\
Ensaio 5 & 0 & 1 & $1048,04 \pm 92,44^{\mathrm{b}}$ & $1366,84 \pm 26,52^{\mathrm{c}}$ & $1823,98 \pm 89,46^{\mathrm{b}}$ \\
Ensaio 7 & 25 & 0 & $1040,18 \pm 44,62^{\mathrm{b}}$ & $1708,77 \pm 117,26^{\mathrm{b}}$ & $1997,19 \pm 192,98^{\mathrm{ab}}$ \\
Ensaio 9 & 25 & 1 & $1080,64 \pm 70,52^{\mathrm{b}}$ & $1496,45 \pm 87,18^{\mathrm{c}}$ & $1841,77 \pm 170,40^{\mathrm{b}}$ \\
\hline
\end{tabular}

Médias seguidas da mesma letra na vertical não diferem significativamente entre si (Teste de Tukey a 95\% de significância).

Tabela 13. Análise de variância - avaliação sensorial.

\begin{tabular}{|c|c|c|c|c|c|c|}
\hline & \multirow[t]{2}{*}{ Lipase (ppm) } & \multirow{2}{*}{$\begin{array}{c}\text { Monoglicerídeo } \\
(\%)\end{array}$} & \multicolumn{4}{|c|}{ Atributos } \\
\hline & & & Aparência & Textura & Aroma & Sabor \\
\hline Controle & 0 & 0 & $6,22 \pm 1,43^{\mathrm{b}}$ & $5,31 \pm 1,55^{c}$ & $6,97 \pm 1,13^{\mathrm{b}}$ & $6,91 \pm 1,33^{\mathrm{a}}$ \\
\hline Ensaio 5 & 0 & 1 & $7,16 \pm 1,20^{\mathrm{a}}$ & $6,72 \pm 1,21^{\mathrm{b}}$ & $7,23 \pm 1,14^{\mathrm{ab}}$ & $7,18 \pm 1,16^{\mathrm{a}}$ \\
\hline Ensaio 7 & 25 & 0 & $7,75 \pm 0,87^{\mathrm{a}}$ & $7,56 \pm 0,97^{\mathrm{a}}$ & $7,78 \pm 0,82^{\mathrm{a}}$ & $7,59 \pm 0,93^{\mathrm{a}}$ \\
\hline Ensaio 9 & 25 & 1 & $7,53 \pm 0,97^{\mathrm{a}}$ & $7,34 \pm 1,16^{\mathrm{ab}}$ & $7,66 \pm 0,96^{\mathrm{a}}$ & $7,53 \pm 1,25^{\mathrm{a}}$ \\
\hline
\end{tabular}

Médias seguidas da mesma letra na vertical não diferem significativamente entre si (Teste de Tukey a 95\% de significância). 
que neste estudo a avaliação sensorial foi realizada no $1^{\circ}$ dia após o processamento, mas é possível que as diferenças sejam mais pronunciadas nos dias 4 e 7 . Também se sugere avaliar o monoglicerídeo e a lipase em uma formulação de pão de forma sem a adição de farelo de trigo, na qual é possível que os efeitos sejam mais perceptíveis.

\section{Referências bibliográficas}

AACC. AMERICAN ASSOCIATION OF CEREAL CHEMISTS. Approved Methods of American Association of Cereal Chemists, 9. ed., v. 1 e 2. St. Paul: Approved Methods Committee, 1995.

AL-EID, S. M.; AL-NESHAWY, A. A.; AL-SHAIKH AHMAD, S. S. Influence of substituting water with ultrafiltered milk permeate on dough properties and baking quality of white pan bread. Journal of Cereal Science, London, v. 30, n. 1, p. 79-82, 1999.

ALMEIDA, E. L. Efeito da adição de fibra alimentar sobre a qualidade de pão pré-assado congelado. 2006, 328p. Dissertação (Mestre em Tecnologia de Alimentos) - Faculdade de Engenharia de Alimentos, Universidade Estadual de Campinas (UNICAMP), Campinas, 2006.

AOAC. Association of Official Analytical Chemists. Official methods of analysis of the AOAC International, 16. ed., v. 1. Arlington: AOAC International, 1995.

BARROS NETO, B.; SCARMINIO, I. S.; BRUNS, R. E. Planejamento e Otimização de Experimentos, 2. ed. Campinas: Editora da UNICAMP, 1996.

BEISSON, F. et al. Methods for lipase detection and assay: a critical review. European Journal of Lipid Science and Technology, Weinheim, v. 102, n. 2, p. 133-153, 2000.

BIONDI, S. H. S. Qualidade da farinha de trigo: conceito, fatores determinantes e parâmetros de avaliação de controle. Campinas: Instituto de Tecnologia de Alimentos - ITAL, p. 41-62, 2003.

BONET, A. et al. Glucose oxidase effect on dough rheology and bread quality: A study from macroscopic to molecular level. Food Chemistry, London, v. 99, n. 2, p. 408-415, 2006.

BORNSCHEUER, U. T. Lipase Catalysed Synthesis of Monoacylglycerols. Enzyme and Microbial Technology, New York, v. 17, n. 7, p. 578-586, 1995.

BRASIL. Ministério da Saúde. Agência Nacional de Vigilância Sanitária. Resolução RDC no 90, 18 out. 2000. Aprova o regulamento técnico para fixação de identidade e qualidade de pão. Diário Oficial da República Federativa do Brasil, Brasília, out. 2000. Disponível em <http://www.anvisa.gov.br/>. Acesso em: 24 abr. 2006.

CALLEJO, M. J. et al. Effect of gluten addition and storage time on white pan bread quality: instrumental evaluation. Z Lebensm Unters Forsch A, Berlin, v. 208, n. 1, p. 27-32, 1999.

CAMPOS, P. R. B. et al. Isolamento e seleção de microorganismos produtores de lipase como biocatalizadores na hidrólise parcial de óleo de sardinha. Revista Lecta, Bragança Paulista, v. 20, n. 1, p. 07-14, 2002.

CARVALHO, P. O. et al. Aplicação de lipases microbianas na obtenção de concentrados de ácidos graxos poliinsaturados. Química Nova, São Paulo, v. 26, n. 1, p. 75-80, 2003.

ESTELLER, M. S. Fabricação de pães com reduzido teor calórico e modificações reológicas ocorridas durante o armazenamento. 2004, 238p. Dissertação (Mestre em Tecnologia de Alimentos) Faculdade de Ciências Farmacêuticas, Universidade de São Paulo (USP), São Paulo, 2004.
FERREIRA, R. E. Avaliação de parâmetros do processo de extrusão e do teor de farelo de trigo adicionado em características de "snacks" expandidos de milho. 2006, 163p. Dissertação (Mestre em Tecnologia de Alimentos) - Faculdade de Engenharia de Alimentos, Universidade Estadual de Campinas (UNICAMP), Campinas, 2006.

GALAL, A. M.; JOHNSON, J. A.; VARRIANO-MARSTON, E. Lactic and volatile (C2-C5) organic acids of San Francisco sourdough French bread. Cereal Chemistry, Saint Paul, v. 55, n. 4, p. 461-468, 1978.

GANDHI, N. N. Applications of lipase. Journal of the American Oil Chemists Society, Chicago, v. 74, n. 6, p. 621-634, 1997.

GIL, M. J. et al. Keeping qualities of white pan bread upon storage: effect of selected enzymes on bread firmness and elasticity. Z Lebensm Unters Forsch A, Berlin, v. 208, n. 5-6, p. 394-399, 1999.

GIMÉNEZ, A. et al. Shelf life estimation of brown pan bread: A consumer approach. Food Quality and Preference, Barking, v. 18, n. 2, p. 196-204, 2007.

GOESAERT, H. et al. Wheat flour constituents: how they impact bread quality, and how to impact their functionality. Trends in Food Science \& Technology, Cambridge, v. 16, n. 1-3, p. 12-30, 2005.

GÓMEZ, M. et al. Functionality of different emulsifiers on the performance of breadmaking and wheat bread quality. Eur. Food Res. Technol., Berlin, v. 219, n. 2, p. 145-150, 2004.

HAROS, M.; ROSELL, C. M.; BENEDITO, C. Effect of different carbohydrases on fresh bread texture and bread staling. Eur. Food Res. Technol., Berlin, v. 215, n. 5, p. 425-430, 2002.

HASAN, F.; SHAH, A. A.; HAMEED, A. Industrial applications of microbial lipases. Enzyme and Microbial Technology, New York, v. 39, n. 2, p. 235-251, 2006.

HOUDE, A.; KADEMI, A.; LEBLANC, D. Lipases and their industrial applications: an overview. Appl. Biochem. Biotechnol., Clifton, v. 118, n. 1-3, p. 155-170, 2004.

INSTITUTO ADOLFO LUTZ. Normas analíticas do Instituto Adolfo Lutz, 2. ed., v. 1. São Paulo: Instituto Adolfo Lutz, 1976.

. Normas analíticas do Instituto Adolfo Lutz, 2. ed., v. 1. São Paulo: Instituto Adolfo Lutz, 1985.

KATINA, K. et al. Effects of sourdough and enzymes on staling of high-fiber wheat bread. LWT-Food Science and Technology, Amsterdam, v. 39, n. 5, p. 479-491, 2006.

KOKELAAR, J. J.; GARRITSEN, J. A.; PRINS, A. Surface rheological properties of sodium stearoyl-2-lactylate (SSL) and diacetyl tartaric esters of mono (and di) glyceride (DATEM) surfactants after a mechanical surface treatment in relation to their bread improving abilities. Colloids and Surfaces A: Physicochemical and Engineering Aspects, Amsterdam, v. 95, n. 1, p. 69-77, 1995.

LAD, P. J.; MULLINS, M. M. Type II endoglycosidases in baking for improving the quality of dough and baked goods. United States Patent 5232719. 08-03-1993.

LEÓN, A. E.; DURÁN, E.; BARBER, C. B. Utilization of enzyme mixtures to retard bread crumb firming. Journal of Agricultural and Food Chemistry, Easton, v. 50, n. 6, p. 1416-1419, 2002.

LIMA, I.; GURAYA, H.; CHAMPAGNE, E. The functional effectiveness of reprocessed rice bran as an ingredient in bakery products. Nahrung/Food, Weinheim, v. 46, n. 2, p. 112-117, 2002.

MATUDA, T. G. Análise térmica da massa de pão francês durante os processos de congelamento e descongelamento: otimização do uso de aditivos. 2004, 142p. Dissertação (Mestre em Engenharia) - Escola Politécnica, Universidade de São Paulo (USP), São Paulo, 2004. 
MELO, L. L. M. M. Síntese enzimática dos ésteres de aroma butirato e valerato de citronelila por lipase de Rhisopus SP. 2004, 94p. Dissertação (Mestre em Ciência de Alimentos) - Faculdade de Engenharia de Alimentos, Universidade Estadual de Campinas (UNICAMP), Campinas, 2004.

NÉRON, S. et al. Separation and quantification by high-performance liquid chromatography with light scattering detection of the main wheat flour phospholipds during dough mixing in the presence of phospholipase. Journal of Chromatography A, Amsterdam, v. 1047, n. 1, p. 77-83, 2004.

POMERANZ, Y. Modern cereal science and technology. New York: VCH, 1987.

PONTES, A. E. R. Desenvolvimento de pão de forma sem adição de açúcares, gorduras e emulsificantes, com o uso de enzimas e amido de mandioca modificado. 2006, 73p. Dissertação (Mestre em Tecnologia de Alimentos) - Faculdade de Engenharia de Alimentos, Universidade Estadual de Campinas (UNICAMP), Campinas, 2006.

POUTANEN, K. Enzymes: An important tool in the improvement of the quality of cereal foods. Trends in Food Science \& Technology, Cambridge, v. 8, n. 9, p. 300-306, 1997.

PYLER, E. J. Baking: science and technology, 3. ed., v. 1. Sosland: Merrian, 1988.

RIBOTTA, P. D. et al. Effect of emulsifier and guar gum on micro structural, rheological and baking performance of frozen bread dough. Food Hydrocolloids, Oxford, v. 18, n. 2, p. 305-313, 2004.
ROSENTHAL, A. J. Food texture: measurement and perception. London: Chapman \& Hall, 1999.

SAHLSTRÕM, S.; BRATHEN, E. Effects of enzyme preparations for baking, mixing time and resting time on bread quality - and bread staling. Food Chemistry, London, v. 58, n. 1-2, p. 75-80, 1997.

STAMPFLI, L.; NERSTEN, B. Emulsifiers in bread making. Food Chemistry, London, v. 52, n. 4, p. 353-360, 1995.

STAUFFER, C. E. Functional additives for bakery foods. New York: AVI Books, 1990.

SZCZESNIAK, A. S. Texture is a sensory property. Food Quality and Preference, Barking, v. 13, n. 4, p. 215-225, 2002.

TAIT, S. P. C.; GALLIARD, T. Effect on baking quality of changes in lipid composition during wholemeal storage. Journal of Cereal Science, London, v. 8, n. 2, p. 125-137, 1988.

TAMSTORF, S.; JONSSON, T.; KROG, N. The role of fats and emulsifiers in baked products. In: BLANSHARD, J. M. V.; FRAZIER, P. J. \& GALLIARD, T. Chemistry and physics of baking. London: The Royal Society of Chemistry, 1987. p. 75-88.

TUROLA, L. B. Desenvolvimento de bolo diet enriquecido com fibras: otimização do produto através de testes sensoriais afetivos. 2002, 88p. Dissertação (Mestre em Alimentos e Nutrição) - Faculdade de Engenharia de Alimentos, Universidade Estadual de Campinas (UNICAMP), Campinas, 2002.

VAN DER MAAREL, M. J. E. C. et al. Properties and applications of starch-converting enzymes of the alpha-amylase family. Journal of Biotechnology, Amsterdam, v. 94, n. 2, p. 137-155, 2002. 